\title{
Principais motivos de desclassificação em licitações públicas: fase de habilitação e proposta
}

A licitação é um procedimento administrativo necessário para contratar determinados tipos de produtos e serviços, onde a administração pública irá escolher a melhor proposta, o processo licitatório é público e quem estar concorrendo ao mesmo deve respeitar as exigências estabelecidas em cada edital. Sabendo disso, este trabalho irá introduzir sobre licitações públicas, de modo a informar sua importância, tipos e modalidades. Explanando as fases de documentação, em relação a habilitação, e as fases de proposta, que normalmente abrangem os orçamentos e planilhas descritas pelo edital. Em seguida, serão apresentadas amostras coletadas em órgãos públicos que realizaram licitações de diversos tipos de serviços. Gerando então uma análise para cada parecer obtido, desta forma classificando os principais motivos para inabilitação ou desclassificação dos participantes. Logo com os resultados alcançados é possivel verificar padrões e orientar devidamente com as informações contidas, onde se deve tomar mais cautela na elaboração da habilitação e das propostas.

Palavras-chave: Desclassificação; Análise; Licitações públicas.

\section{Main reasons for declassification in public tenders: qualification and proposal phase}

Bidding is an administrative procedure necessary to contract certain types of products and services, where the public administration will choose the best bid, the bidding process is public and anyone bidding for it must comply with the requirements established in each public notice. Knowing this, this paper will introduce about public tenders, in order to inform their importance, types and modalities. Explaining the documentation phases, in relation to the qualification, and the proposal phases, which usually cover the budgets and spreadsheets described by the notice. Subsequently, samples collected from public agencies that bid fo various types of services will be presented. Generating an analysis for each opinion obtained, thus classifying the main reasons for disqualification or disqualification of participants. With the results achieved it is possible to check standards and guide properly with the information contained, where more caution should be taken in preparing the qualification and proposals.

Keywords: Downgrading; Analyze; Public bids.

Topic: Direito Administrativo

Reviewed anonymously in the process of blind peer.
Received: 25/11/2019

Approved: 07/04/2019
Danielle Cristina dos Santos Lisboa (iD Centro Universitário Dom Bosco, Brasil http://lattes.cnpq.br/3350912872257730 http://orcid.org/0000-0001-8707-2442 daniellecristinaeng@gmail.com

Misael Vieira dos Santos

Centro Universitário Dom Bosco, Brasi http://lattes.cnpq.br/4249885598347103

http://orcid.org/0000-0001-6650-8913 misaelvieira@live.com

Lucas Nadler Rocha (it)

Centro Universitário Dom Bosco, Brasi http://lattes.cnpq.br/8693441362635767

http://orcid.org/0000-0003-1424-2054 lucasnadlerrocha@gmail.com
Lucas dos Santos Zenkner (iD)

Centro Universitário Dom Bosco, Brasil http://lattes.cnpq.br/7556110688320963 http://orcid.org/0000-0002-9408-3833 lucaszenkner1@hotmail.com

Matheus Oliveira Sena

Centro Universitário Dom Bosco, Brasil http://lattes.cnpq.br/6139273453591965 http://orcid.org/0000-0001-5146-2748 matheus osena@hotmail.com

José Murilo Moura dos Reis

Centro Universitário Unidade de Ensino Superior Dom Bosco, Brasil

http://lattes.cnpq.br/7167725628264537 http://orcid.org/0000-0001-8149-1750 eng.jmuriloreis@gmail.com
Renata Medeiros Lobo Muller (it)

Centro Universitário Dom Bosco, Brasil http://lattes.cnpq.br/236674212445033 http://orcid.org/0000-0001-5202-837X renata.muller@undb.edu.br

Claudemir Gomes de Santana

Centro Universitário Dom Bosco, Brasil http://lattes.cnpq.br/0005464426041071 http://orcid.org/0000-0003-0917-2936 csantana0405@gmail.com d

DOI: 10.6008/CBPC2318-3039.2019.001.0003
Referencing this:

LISBOA, D. C. S.; SANTOS, M. V.; ROCHA, L. N.; ZENKNER, L. S.; SENA, M. O.; REIS, J. M. M.; MULLER, R. M. L.; SANTANA, C. G.. Principais motivos de desclassificação em licitações públicas: fase de habilitação e proposta. Scientiam Juris, v.7, n.1, p.26-43, 2019. DOI: http://doi.org/10.6008/CBPC2318-3039.2019.001.0003 


\section{INTRODUÇÃO}

Segundo Torres (2015), licitação é o procedimento prévio de seleção pelo qual a administração, com regularidade em critérios estabelecidos, isonômicos, aberto as empresas que desejam competitividade, buscando melhor opção para realizar um contrato com a empresa. Para os autores Alexandre et al. (2017), a licitação é essencial antes de celebrar um contrato administrativo, abrindo a todos os interessados que pretendem contratar e que atendam as condições previstas em lei (Lei 8.666/93). Dando as mesmas a oportunidade de mostrar suas propostas, com objetivo de que seja escolhida a que melhor atender o interesse público.

A constituição federal deixa expressa em seu artigo 37, XXI; a obrigatoriedade em realizar licitação em obras, serviços, compras e alienações. Assegurando a igualdade entre todos os concorrentes, com cláusulas estabelecida em lei. Porém, existe hipóteses que a realização de licitação é impossível ou frustra o interesse público, nestes casos a lei possibilita que a Administração realize contrato direto (sem licitação), ocorrendo em virtude da inexigibilidade ou da dispensa da própria licitação.

Segundo a Lei de Licitações Públicas, a empresa que quiser participar do certame de licitação poderá tentar nas modalidades de convite, concorrência, tomada de preço, pregão, leilão, concurso, sendo que o pregão foi criado pela Lei $10.520 / 2002$. Outra modalidade que também foi criada posterior a Lei 8.666 foi a RDC (Regime Diferenciado de Contratação), pela Lei 12.462 de 2011, que foi criada para atender a Copa do Mundo de 2016, que desde então continuou sendo usada.

As empresas participam das modalidades das licitações para que possam conseguir uma obra, ou objeto de trabalho, logo abre o campo da concorrência entre as empresas, e seguindo o edital e leis regulamentadoras, nas fases de habilitação e propostas, as empresas tentam desclassificar, encontrar brechas, falhas na habilitação e propostas de suas concorrentes para ficarem com o objeto licitado.

Assim como dito, para as empresas novas, sem a experiência em quais itens deve-se tomar mais cuidado, itens que costumam estar o tempo todo atualizando, o estudo tem como finalidade abrir um leque de possibilidades, que pode-se tomar cuidado devido, fazendo assim uma análise de algumas atas de julgamento disponíveis pelos órgãos públicos, na qual será exposto no estudo.

Segundo Carvalho Filho (2015), no livro em sua autoria, Manual de Direito Administrativo, o participante da licitação será aquele que apresentar um menor valor para o objeto licitado, porém não será aceito propostas com valores inexequíveis ou financeiramente incompatíveis com os fins do certame, sendo diretamente desclassificadas.

Com as informações coletadas durante o estudo, ao fim se pretende chegar a uma análise e ter ideia de como funciona todo o processo licitatório, podendo passar informações importantes para outras pessoas que desejam seguir com o intuito de participar das licitações públicas. Realizando uma análise dos erros mais cometidos nas propostas de habilitação de licitação levando análise em dos erros cometidos pelos licitantes através de resultados de licitações já ocorridas propondo onde certos erros devem ser corrigidos no processo licitatório. 


\section{METODOLOGIA}

\section{Tipo de pesquisa}

Trata-se de uma pesquisa comparativa, com dados coletados por meio de processos licitatórios. A pesquisa será baseada através de atas de julgamento das propostas, tendo informações coletadas pelos sites dos órgãos públicos como, Sinfra (Secretaria de Infraestrutura do Maranhão), da CPL (Central de Licitações da Prefeitura) e pelo Tribunal de Justiça do Maranhão e outros órgãos públicos em que consiga extrair essas informações, na ânsia de obter dados suficientes para pesquisa e análise de grau relevante, pois pode-se deparar casos localizados isolados, que no caso não acrescentará na pesquisa.

\section{Local de estudo}

O estudo de caso será realizado através das licitações verificando as atas e resultados após análise dos setores de engenharia dos órgãos públicos em que participou. Toda licitação após a fase da entrega das propostas, executa o julgamento das propostas das licitantes junto com justificativas em caso de desclassificação, dando prazo de até 5 dias para a empresa caso desclassificada entrar com recurso, logo nesses documentos de julgamento das propostas em que faremos nosso estudo.

\section{Coleta de dados}

A coleta de dados será executada através do recolhimento de atas e resultados do julgamento de licitações ocorridas, através do site do órgão público que disponibiliza para o público, pois tais informações devem ser de conhecimento aos que buscam por elas. Este trabalho será realizado por meio de revisões bibliográficas, pontuando alguns comentários do autor sobre o determinado assunto aqui questionado. Foram utilizados como referencial teóricos os trabalhos de autores reconhecidos no meio acadêmico, como Ronny Charles em 'Leis de licitações Públicas comentadas', Benedicto de Tolosa Filho em 'Licitações comentários, teoria e prática', além de consultas a atas, resultados de julgamento de licitações e a própria lei de licitação n 8.666/93 (TOLOSA FILHO, 1997).

\section{Análise de dados}

Para a análise de dados será feito a coleta das atas e resultados, para verificar-se os motivos de desclassificação das empresas participantes e relatar um estudo para que se defina uma probabilidade de que a empresa cometa certos erros. Tendo como interesse coletar 9 (onze) amostras no intervalo de 2 anos, 2016 a 2018, sendo licitações realizadas nos órgãos públicos do Maranhão, dos principais órgãos de São Luís na tentativa de obter um resultado mais completo, as licitações todas serão do tipo menor preço e com modalidades sendo tomada de preço ou concorrência, todas as amostras coletadas apresentam uma inabilitação de alguma empresa, que mostrem desclassificação das empresas, para que assim tenha uma porcentagem na qual irá apresentar qual motivo mais se repete, impossibilitando a empresa de sair como vencedora. Esse projeto será devidamente autorizado pelo diretor da empresa, assim como os órgãos 
públicos na qual ocorre a coleta dos dados para estudo, além de que em questões de licitações públicas, pode ser de domínio público tais informações.

\section{RESULTADOS}

\section{Amostra 1}

Para a primeira amostra, foi coletado os dados da licitação da AGERP (Agência Estadual de Pesquisa Agropecuária e Extensão Rural do Maranhão), tipo de menor preço sob regime da modalidade tomada de preço $n^{\circ} 01$ de 2018, abertura do certame ocorreu no dia 23 de agosto de 2018, no horário das 15:30. 0 objeto desta licitação é a contratação de empresa de engenharia para prestação de serviços especializados de reforma do prédio sede da Agência Estadual de Pesquisa Agropecuária e Extensão Rural do Maranhão AGERP/MA, localizado à Rua Granja Barreto, S/N - Outeiro da Cruz - São Luís/MA, orçado pelo órgão público

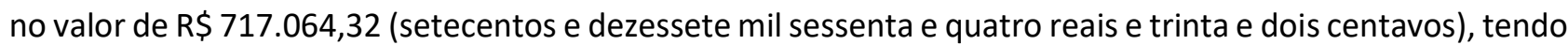
no seu cronograma o prazo de 5 (cinco) meses, para executar a obra.

\begin{tabular}{|c|}
\hline $\begin{array}{l}\text { AVISO DE JULGAMENTO DA HABILITAÇÃO } \\
\text { PROCESSO ADMINISTRATIVO N 094056/2018 - AGERP } \\
\text { TOMADA DE PREÇOS N 001/2018 - AGERP }\end{array}$ \\
\hline $\begin{array}{l}\text { A Comissão Setorial de Licitação da Agência Estadual de Pesquisa } \\
\text { Agropecuária e Extensão Rural do Maranhão - AGERPIMA, torna público o } \\
\text { resultado do julgamento dos documentos de habilitação da licitação em epígrafe, } \\
\text { cujo objeto é a Contratação de empresa de engenharia para prestação de } \\
\text { serviços especializados de reforma do prédio sede da Agência Estadual de } \\
\text { Pesquisa Agropecuária e Extensão Rural do Maranhão - AGERPIMA. A } \\
\text { Comissão declara HABILITADA a empresa CONPAC - Construções e } \\
\text { Consultoria LTDA-EPP, CNPJ n 05.909.446/0001-57, restando INABILITADAS } \\
\text { as empresas: 1- EEMA - Empreendimentos de Engenharia do Maranhão } \\
\text { LTDA-ME; 2- AGC Engenharia LTDA-EPP; 3- ETECH Construções LTDA-ME; } \\
\text { 4- BASE Engenharia LTDA-ME; 5- DINAMARCA Empreendimentos da } \\
\text { Construção e Indústria Gráfica LTDA-EPP; 6- ARENITO Construção LTDA- } \\
\text { ME; 7- G4 Empreendimentos e Serviços LTDA-EPP; 8- O. B. S. Pinto } \\
\text { Engenharia EIRELI e 9- INGARANA Construções LTDA-ME. }\end{array}$ \\
\hline $\begin{array}{l}\text { Comunicamos que fica aberto o prazo para interposição de recurso, } \\
\text { nos termos do Art. 109, inciso I, alínea "a", da Lei Federal no } 8.666 / 1993 \text { e que os } \\
\text { autos do processo administrativo licitatório permanecerão com vista franqueada } \\
\text { aos interessados na Sala da Comissão Setorial de Licitação, localizada na Rua } \\
\text { Sete de Setembro, } n^{\circ} 43 \text { - Centro, São Luís/MA, na data de publicação no site da } \\
\text { CCL: www.ccl.ma.gov.br, conforme consignado na ata da sessão. }\end{array}$ \\
\hline São Luís/MA, 13 de setembro de 2018. \\
\hline
\end{tabular}

Figura 1: Aviso de julgamento da habilitação.

Para a realização desta obra, as empresas interessadas em participar teriam que constar em seus acervos, quantidade de construção mais relevantes da planilha fornecida, no edital menciona ainda que os itens mais relevantes da obra, podem ser vistos na curva $A B C$ de serviços, que como visto, o ' $A$ ' representa $50 \%$ do valor da planilha, logo, se o orçamento está em $717.064,32$ reais, os itens mais relevantes seria o somatório dos serviços até o valor 358.532,16 (Trezentos e cinquenta e oito mil, quinhentos e trinta e dois reais e dezesseis centavos), organizando-os de forma decrescente.

Esses quantitativos deveriam constar na Certidão de Acervo Técnico (CAT) comprovando que a 
empresa executou esses serviços, além de que deveria apresentar também no seu quadro técnico, profissionais com a comprovação de acompanhamento e ou execução desses serviços ou parecidos. Na Figura 1 abaixo podemos uma ata de aviso de julgamento que a empresa CONPAC foi a escolhida.

$\mathrm{Na}$ ata de julgamento acima é possível identificar que participaram 10 empresas, porém apenas a empresa Conpac Construções e Consultoria LTDA foi habilitada, pois as demais empresas haviam sido desclassificadas por falta de assinatura do engenheiro eletricista ou não apresentar no quadro da empresa, pois para os serviços de elétrica da obra era necessário apresentar o engenheiro eletricista participante da empresa. É válido notar que na presente licitação, foi solicitado ainda nos documentos de habilitação o DFL, que em comparação a concorrência nº02 de 2018, da Procuradoria Geral, não solicitou tal documento. De acordo com o edital da AGERP tomada de preço $\mathrm{n}^{\circ} 01$ de 2018 se tem:

$$
D F L=((n x C F A)) / 12-V A
$$

Onde:

DFL = Disponibilidade Financeira Líquida $\mathrm{n}=$ prazo em meses estipulado para a execução dos serviços objeto deste Edital CFA = Capacidade Financeira Anual

$\mathrm{Va}=$ somatório dos valores residuais dos contratos ora a cargo da licitante, calculado a partir dos saldos contratuais atualizados monetariamente para o mês da data base da proposta de preços, pelos índices setoriais de reajustamento, utilizando-se para 11 o índice do mês da data base da licitação e para 10 o índice correspondente ao mês da data da proposta de cada contrato. Os valores residuais serão apropriados 'pró-rata' aos ' $n$ ' meses de execução contratual nos casos em que os prazos residuais dos contratos em andamento ultrapassarem o prazo de execução estipulado para os serviços em Licitação.

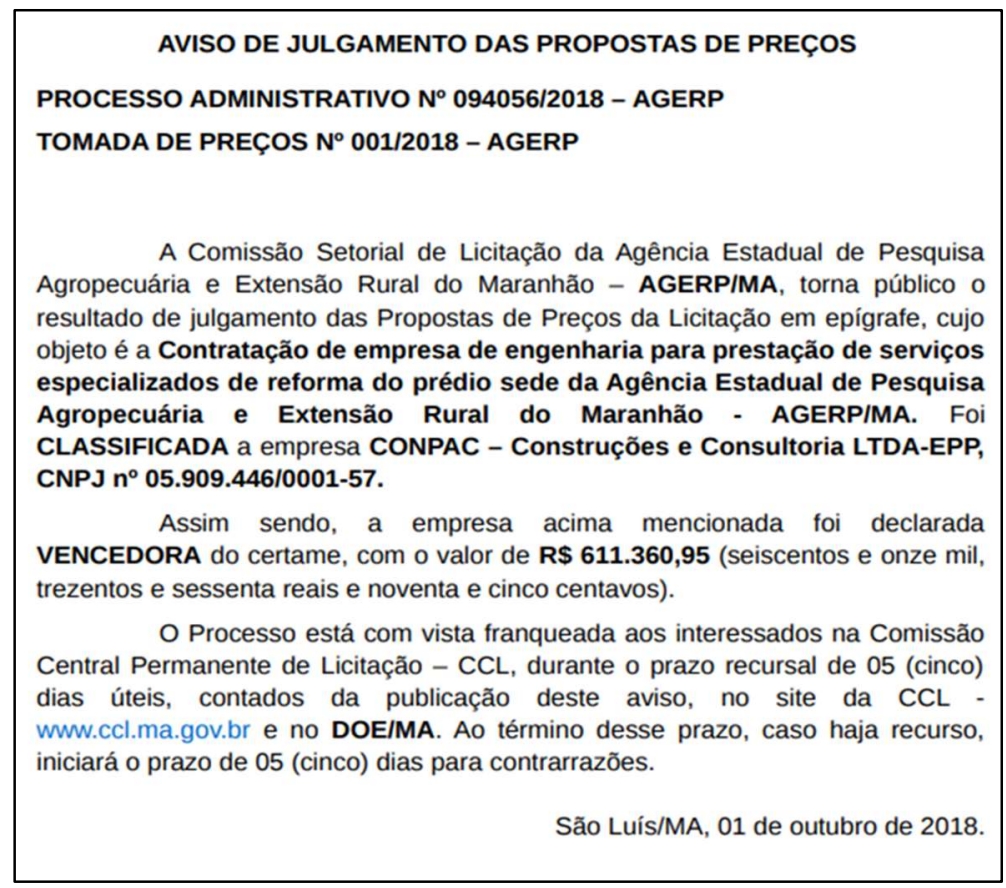

Figura 2: Ata de julgamento das propostas.

No tramite da licitação pública, após a fase da habilitação, as empresas são chamadas após a análise dos documentos e dado os resultados de quem foi habilitada e quem foi inabilitada, tendo a empresa inabilitada o direito de recorrer em até 05 (cinco) dias úteis. Como visto no julgamento da habilitação, apenas a empresa Conpac passou para a segunda. De acordo com a Figura 2 abaixo temos a ata da proposta de julgamento. A empresa Conpac, conseguiu a obra pelo valor de 611.360,95 (Seiscentos e onze mil, trezentos 
e sessenta reais e noventa e cinco centavos), tendo reduzido uma porcentagem de:

$$
\text { RED }=611 \cdot 360,95 / 717 \cdot 064,32=0,85 \%
$$

Ou seja, com o valor de $15 \%$ a menos do imposto pelo órgão. Onde, RED é a porcentagem de redução que a empresa reduziu no orçamento para participar da licitação. Logo a empresa conseguiu ganhar a licitação e no momento aguarda apenas para assinar contrato e dar início ao serviço logo após a emissão da ordem de serviço.

\section{Amostra 02}

Para a segunda amostra, foi coletado os dados da licitação do Tribunal de Justiça do Maranhão, tipo de menor preço sob regime da modalidade concorrência $n^{\circ} 06$ de 2018, abertura do certame ocorreu no dia 29 de agosto de 2018. O objeto desta licitação é a contratação de empresa de engenharia para prestação de serviços especializados na Construção do salão do júri da comarca de Pindaré Mirim/MA, orçado pelo órgão público no valor de e $\mathrm{R} \$ 595.954,40$ (quinhentos e noventa e cinco mil novecentos e cinquenta e quatro reais e quarenta centavos, tendo no seu cronograma o prazo de 5 (cinco) meses, para executar a obra.

Quadro 1: Julgamento de habilitação das empresas.

\begin{tabular}{|c|c|}
\hline $\mathrm{N}^{\circ}$ & EMPRESAS \\
\hline 01 & CONPAC CONSTRUÇÕES E CONSULTORIA LTDA (HABILITADA) \\
\hline 02 & $\begin{array}{l}\text { VERSAL CONSTRUÇÕES E CONSULTORIA LTDA (INABILITADA) } \\
\text { - } \quad \text { Não comprovou o exigido no item 7.1.4.1, “I" (Cobertura metálica: 71,0m²); } \\
\text { - } \quad \text { Não comprovou o exigido no item 7.1.4.1, "II" (Cobertura); } \\
\text { Não apresentou o exigido no item 7.1.4.1, "IV" (declaração de compromisso de contratação futura referente ao } \\
\text { profissional- Engenheiro Eletricista) }\end{array}$ \\
\hline 03 & PALMARES CONSTRUÇÕES LTDA (HABILITADA) \\
\hline 04 & $\begin{array}{l}\text { CAMPOS CONSTRUÇÕES LTDA-EPP (INABILITADA) } \\
\text { - } \quad \text { Não comprovou o exigido no item 7.1.4.1, “I” (Estrutura metálica p/cobertura: 700,00kg ou 71,0m²); } \\
\left.\text { - } \quad \text { Não comprovou o exigido no item 7.1.4.1, “I" (Cobertura metálica: } 71,0 \mathrm{~m}^{2}\right) ; \\
\text { - } \quad \text { Não comprovou o exigido no item 7.1.4.1, “II" (Estrutura metálica p/ cobertura); } \\
\text { Não comprovou o exigido no item 7.1.4.1, "II" (Cobertura); }\end{array}$ \\
\hline 05 & $\begin{array}{l}\text { QUALITECH ENGENHARIA LTDA (INABILITADA) } \\
\text { - Não apresentou o exigido no item 7.1.4.1, “IV" (declaração de compromisso de contratação futura referente ao } \\
\text { profissional- Engenheiro Eletricista) }\end{array}$ \\
\hline 06 & TPCO ENGENHARIA LTDA (HABILITADA) \\
\hline 07 & $\begin{array}{l}\text { NORTE BRASIL CONSTRUÇÕES LTDA-EPP (INABILITADA) } \\
\text { - } \quad \text { Não comprovou o exigido no item 7.1.4.1, “I” (Estrutura metálica p/cobertura: 700,00kg ou 71,0m²); } \\
\text { - } \quad \text { Não comprovou o exigido no item 7.1.4.1, “I" (Cobertura metálica: 71,0m²); } \\
\text { - } \quad \text { Não comprovou o exigido no item 7.1.4.1, "II" (Estrutura metálica p/ cobertura); } \\
\text { Não comprovou o exigido no item 7.1.4.1, “II" (Cobertura); }\end{array}$ \\
\hline 08 & PENHA CONSTRUÇÕES E SERVIÇOS LTDA-ME (HABILITADA) \\
\hline 09 & TORQUATO FERNANDES CONSTRUÇÕES E IMOBILIÁRIA LTDA (HABILITADA) \\
\hline 10 & 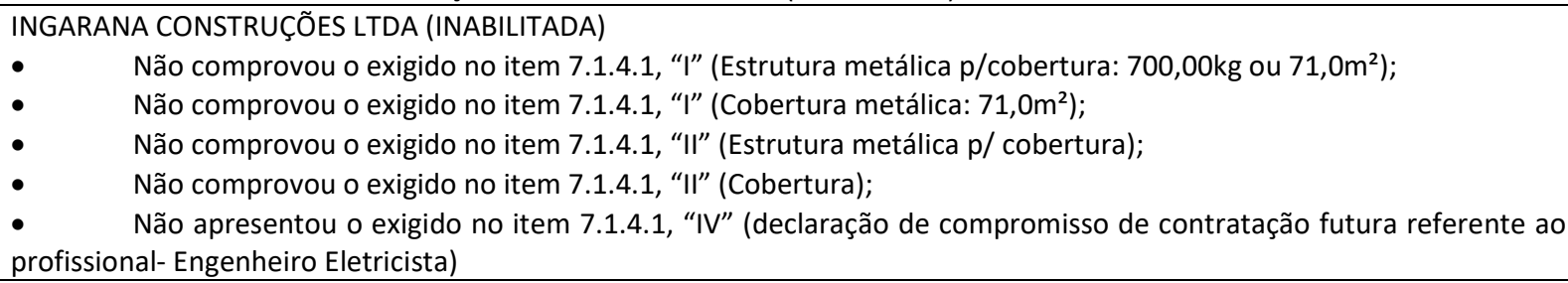 \\
\hline
\end{tabular}

Legenda: Tribunal de Justiça do Maranhão (2018).

Para a realização desta obra, as empresas interessadas em participar teriam que constar em seus acervos: • Reboco cimento e areia: 515,0m²; • Alvenaria em tijolo cerâmico: 225,0m³; • Estrutura metálica para cobertura: $620,00 \mathrm{~kg}$ ou $78,0 \mathrm{~m}^{2}$; • Cobertura metálica: $78,0 \mathrm{~m}^{2}$; • Concreto estrutural fck $20 \mathrm{Mpa}$ ou 
superior: $10,5 \mathrm{~m}^{3}$.

Esses quantitativos deveriam constar na CAT, comprovando que a empresa executou esses serviços, além de que deveria apresentar também no seu quadro técnico, profissionais com a comprovação de acompanhamento e ou execução desses serviços ou parecidos. Na data 14 de setembro de 2018, foi divulgado a ata de julgamento da habilitação das empresas, que ficou da seguinte forma, no Quadro 2 abaixo podemos observar o julgamento das empresas.

No Quadro 1, vimos que muitas ou praticamente todas foram desclassificadas por falta de acervo técnico, dos serviços solicitados no edital, ficando apenas as empresas Conpac, Palmares, TPCO, Penha e Torquato para a próxima etapa da licitação, que até a data 27 de outubro ainda não ocorreu. Apenas na fase de habilitação foi notado que $50 \%$ das empresas foram desclassificadas, isso se deu pois os serviços de estrutura metálica e a cobertura metálica, não são serviços comuns para a nossa região, acabando que diminua a concorrência entre as empresas, principalmente se forem empresas novas no ramo.

\section{Amostra 03}

Para a terceira amostra, foi coletado os dados da licitação da SINFRA (Secretaria de estado de infraestrutura do Maranhão), tipo de menor preço sob regime da modalidade concorrência n 072 de 2017, abertura do certame ocorreu no dia 31 de agosto de 2017, às 15:00 horas. O objeto desta licitação é a contratação de empresa especializada para concluir os serviços remanescentes na unidade mista do Maiobão, em São Luís/MA, orçado pelo órgão público no valor de $\mathrm{R} \$$ 5.123.897,67 (cinco milhões, cento e vinte e três mil, oitocentos e noventa e sete reais e sessenta e sete centavos), tendo no seu cronograma o prazo de 8 (oito) meses, para executar a obra.

Para a realização desta obra, as empresas interessadas em participar teriam que constar em seus acervos: • Montagem de central de ar medicinal comprimido, tendo executado 01 (um); • Alvenaria de vedação de blocos cerâmicos tendo executado $1.210,00 \mathrm{~m}^{2}$; • Cobertura em telha cerâmica tipo canal tendo executado $1.310,00 \mathrm{~m}^{2}$.

Quadro 2: Relação de preços das propostas.

\begin{tabular}{|l|l|}
\hline CONPAC & R\$ 3.739.676,72 (Três milhões, setecentos e trinta e nove mil, seiscentos e setenta e seis reais e setenta e dois reais) \\
\hline J.Menezes & $\begin{array}{l}\text { R\$ 4.544.592,76 (Quatro milhões, quinhentos e quarenta e quatro mil, quinhentos e noventa e dois reais e setenta } \\
\text { e seis centavos) }\end{array}$ \\
\hline ATHOS & $\begin{array}{l}\text { R\$ 4.728.251,98 (Quatro milhões, setecentos e vinte e oito mil, duzentos e cinquenta e um reais e noventa e oito } \\
\text { centavos) }\end{array}$ \\
\hline Quartzo & $\begin{array}{l}\text { R\$ } 4.880 .751,81 \text { (Quatro milhões, oitocentos e oitenta mil, setecentos e cinquenta e um reais e oitenta e um } \\
\text { centavos) }\end{array}$ \\
\hline
\end{tabular}

Legenda: SINFRA.

Esses quantitativos deveriam constar na CAT, comprovando que a empresa executou esses serviços, além de que deveria apresentar também no seu quadro técnico, profissionais com a comprovação de acompanhamento e ou execução desses serviços ou parecidos. Para a fase de propostas foram classificadas 4 (quatro) empresas, que foram a Conpac, Quartzo, J. Meneses Construções LTDA e a Athos Construções LTDA, as empresas deram os preços seguintes para a propostas expostas no Quadro 3 abaixo. 
As empresas participantes reduziram seus valores respectivamente de $27,01 \%$ da Conpac, $13,30 \%$ da empresa J. Menezes, 7,72\% da empresa Athos e 4,74\% da empresa Quartzo. Porém na ata do dia da abertura das propostas foram alegados vários erros encontrados nas propostas, porém tais erros foram acolhidos e nomeado a empresa Athos como vencedora.

\begin{tabular}{|c|c|}
\hline EMPRESA & ALEGAÇÃO \\
\hline CONPAC CONSTRUÇŌES E CONSULTORIA & $\begin{array}{l}\text { QUE A EMPRESA J. MENEZES CONSTRUÇÕES LTDA } \\
\text { DEIXOU DE APLICAR OS } 15 \% \text { REFERENTE A MÃO DE } \\
\text { OBRA DO ELETRICISTA; QUE FOI APLICADO EM } \\
\text { DIVERGÊNCIA O VALOR DA MÃO DE OBRA PARA }\end{array}$ \\
\hline - n............ & 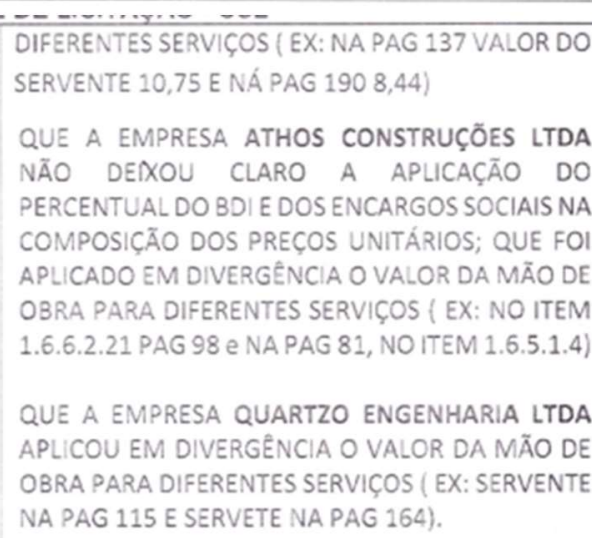 \\
\hline QUARTZO ENGENHARIA LTDA & NÃO CREDENCIADA \\
\hline
\end{tabular}

Figura 3: Alegação da empresa Conpac.

Das empresas participantes da fase da proposta, apenas a empresa Athos teve sua proposta isenta de erros, as demais tiveram erros como, a Conpac entregou planilha desatualizada, pois houve alteração na planilha orçamentaria, que antes tinha seu valor de 4 milhões, sendo assim desclassificada. A empresa J. Menezes deixou de aplicar os $15 \%$ na mão de obra do eletricista.

\section{Amostra 04}

Para a quarta amostra, foi coletado os dados da licitação da SINFRA (Secretaria de estado de infraestrutura do Maranhão), tipo de menor preço sob regime da modalidade concorrência $\mathrm{n}^{\circ} 031$ de 2016 , abertura do certame ocorreu no dia 22 de novembro de 2016, às 09:30. O objeto desta licitação é a contratação de empresa de engenharia para a execução da conclusão da obra de reforma e ampliação do prédio do 6을 BPM, localizado na avenida este, unidade 103, s/n, cidade operária, São Luís/MA, orçado pelo órgão público no valor de R\$ 1.404.043,96 (um milhão, quatrocentos e quatro mil, quarenta e três reais e noventa e seis centavos), tendo no seu cronograma o prazo de 5 (cinco) meses, para executar a obra. Para a realização desta obra, as empresas interessadas em participar teriam que constar em seus acervos: • Piso de alta resistência, tendo executado $800 \mathrm{~m}^{2}$; • Execução de pavimentação em bloco de concreto, tendo executado $500 \mathrm{~m}^{2}$.

Esses quantitativos deveriam constar na CAT, comprovando que a empresa executou esses serviços, além de que deveria apresentar também no seu quadro técnico, profissionais com a comprovação de 
acompanhamento e ou execução desses serviços ou parecidos.

Um diferencial em relação a outros editais de outros órgãos públicos, é que os da SINFRA, é exigido em CD-ROM a planilha em Excel, para que facilite para a comissão analisar se a planilha da proposta não tem preço único acima do fornecido pelo órgão, com isso facilmente identifica-se alguma divergência entre valores e quantitativos, e a ausência do CD-ROM está imediatamente desclassificada. No certame foi o caso da empresa Andrade Variedades Construção LTDA, que foi desclassificada por descumprir o item 15.1, alínea ' $\mathrm{g}$ ' do edital, justamente sobre a entrega do CD-ROM e outro motivo para a desclassificação da empresa seria a ausência da assinatura do contador no documento de Bonificação e Despesas Indiretas-BDI, na qual tem procedimento, contudo não indicou para a comissão motivo desclassificatório, visto que havia sido assinado pelo representante legal da empresa no mencionado documento.

Logo das participantes desta licitação sendo a Conpac Construções e Consultoria LTDA, Andrade Variedades e Construções LTDA e a empresa EBL Construções LTDA, ficaram apenas a Conpac e EBL, porém tratando-se de menor preço a Conpac ofertou o valor de R\$1.189.924,03 ( um milhão cento e oitenta e nove mil, novecentos e vinte e quatro reais e três centavos), contra $\mathrm{R} \$ 1.193 .437,36$ ( um milhão cento e noventa e três mil, quatrocentos e trinta e sete reais e trinta e seis centavos) da EBL, uma diferença pouca de $R \$$ 3.513,33 ( três mil, quinhentos e treze reais e trinta e três centavos) apenas. Sendo assim a empresa Conpac vencedora.

\section{Amostra 05}

Para a quinta amostra, foi coletado os dados da licitação da Comissão Central Permanente de Licitação - CCL, no Auditório Benedito Dutra Mendonça, na Rua 44, quadra 18, n. 35, loteamento Calhau, bairro Calhau, São Luís/MA, tipo de menor preço sob regime da modalidade concorrência № 006/2016 CEL/CCL/MA,), tipo de menor preço sob regime da modalidade concorrência $\mathrm{n}^{\circ} 031$ de 2016, abertura do certame ocorreu no dia 18 de janeiro de 2017, às 09:00 horas.

O objeto desta licitação é a Contratação de Empresa de Engenharia para construção de Cozinhas Comunitárias, no Âmbito do Programa Viva Maranhão: Investimentos Integrados para o Desenvolvimento Sócio inclusivo, nos Municípios de Primeira Cruz, Santo Amaro do Maranhão, Belágua, Milagres do Maranhão, Santana do Maranhão, Água Doce e Araioses, financiados com recursos de operação de crédito CONTRATADA com o Banco Nacional de Desenvolvimento Econômico e Social (BNDES), de interesse da Secretaria de Estado de Desenvolvimento Social - SEDES, em São Luís /MA, orçado pelo órgão público no valor de R\$ 5.249.668,06 (Cinco Milhões Duzentos e Quarenta e Nove Mil, Seiscentos e sessenta e Oito Reais e Seis (entavos), sendo que esse valor é o valor total para as sete obras. Na Tabela 1 temos os valores parciais das obras.

Para a realização desta obra, as empresas interessadas em participar teriam que constar em seus acervos: - Concreto Armado $20 \mathrm{Mpa}$, tendo executado $37,73 \mathrm{~m}^{3}$; - Alvenaria de vedação em blocos cerâmicos, tendo executado 359,42 m²; • Revestimento Cerâmico tendo executado 295,80 m²; • Piso de alta resistência, tendo executado $295,80 \mathrm{~m}^{2}$. 
Tabela 1: Valores parciais das obras.

\begin{tabular}{|c|c|c|c|}
\hline Lote 01 & Municípios & Valor unitário & Valor do lote \\
\hline \multirow{7}{*}{01} & PRIMEIRA CRUZ & $749.807,38$ & \multirow{7}{*}{$5.249 .668,06$} \\
\hline & SANTO AMARO, DO MARANHÃO & $749.807,38$ & \\
\hline & BELAGUA & $749.807,38$ & \\
\hline & MILAGRES DO MARANHÃO & $749.355,12$ & \\
\hline & SANTANA DO MARANHÃO & $749.807,38$ & \\
\hline & ÁGUA DOCE & $751.276,04$ & \\
\hline & ARAIOSES & $749.807,38$ & \\
\hline
\end{tabular}

Legenda: Maranhão - concorrência $n^{\circ} 031$ (2016).

Esses quantitativos deveriam constar na CAT, comprovando que a empresa executou esses serviços, além de que deveria apresentar também no seu quadro técnico, profissionais com a comprovação de acompanhamento e ou execução desses serviços ou parecidos. Na fase de habilitação, não houve desclassificação das empresas, logo foi dado procedimento ao certame para a abertura das propostas. Na Tabela 2 temos as propostas de acordo com cada empresa com seus respectivos valores globais.

Tabela 2: Propostas das empresas.

\begin{tabular}{|l|l|l|}
\hline Ordem & Empresa & $\begin{array}{l}\text { Valor glo } \\
\text { bal }\end{array}$ \\
\hline 01 & Consórcio Lençóis Maranhenses & $4.374 .073,84$ \\
\hline 02 & Consórcio RAMPA LTDA-EPP & $4.499 .128,91$ \\
\hline 03 & CRISTAL Engenharia LTDA & $4.924 .225,10$ \\
\hline 04 & CONPAC Construções e Consultoria LTDA & $4.949 .686,87$ \\
\hline
\end{tabular}

Legenda: Maranhão - concorrência 006 (2016).

As propostas da empresa CRISTAL E CONPAC, não atenderam ao edital, descumprindo o item 7.1, alínea ' $\mathrm{B}$ ' e ' $\mathrm{C}$ ', não detalhando a composição de preço unitário nos itens 1.2 (elaboração do projeto estrutural); 1.3 (sondagem do terreno); 1.5 (ligação provisória de água e esgoto); 1.6 (ligação provisória de energia elétrica e 22.5 (aquisição e instalação da fachada do prédio de logomarca em letreiro luminoso em auto relevo), e ainda a empresa que não apresentou a composição de encargos sociais para trabalhador horista, erro de cálculo no produto entre quantitativo e preço unitário 3.4 (lastro de concreto magro, e=5cm, preparo, inclusive aditivo), na planilha orçamentária do município de Milagre do Maranhão, a SEDES, que foi responsável pela análise das propostas, no parecer técnico não deixou claro qual empresa deixou de cumprir essas ultimas inconsistências. Após as empresas não apresentarem alegações, o órgão anunciou que o consórcio Lençóis Maranhenses foi a vencedora da licitação.

\section{Amostra 06}

Para a sexta amostra, foi coletado os dados da licitação da Tribunal de Justiça do Maranhão, tipo de menor preço sob regime da modalidade concorrência $n^{\circ} 02$ de 2016, abertura do certame ocorreu no dia 30 de setembro de 2016 às 10:00 horas. $O$ objeto desta licitação é a contratação de empresa especializada para concluir o Fórum da Comarca de Santa Helena/MA e serviços de cobertura metálica SPDA do Fórum da Comarca de Santa Luzia/MA de acordo com o projeto básico, orçado pelo órgão público no valor de R\$ 760.181,49 (Setecentos e sessenta mil, cento e oitenta e um reais e quarenta e nove centavos), a licitação dividida em 02 lotes. 
Tabela 3: Valor dos Lotes.

\begin{tabular}{|l|l|l|}
\hline Lote & Objeto & Valor \\
\hline Lote 01 & Conclusão do Fórum da Comarca de Santa Helena/MA & $\mathrm{R} \$ 613.827,26$ \\
\hline Lote 02 & Cobertura Metálica e SPDA do Fórum da Comarca de Santa Luzia & $\mathrm{R} \$ 146.354,23$ \\
\hline Total dos Lotes & & $\mathrm{R} \$ 760.181,49$ \\
\hline
\end{tabular}

Legenda: Maranhão - concorrência n. 02 (2016).

Para a realização desta obra, as empresas interessadas em participar teriam que constar em seus acervos o equivalente aos serviços de: • Piso ou revestimento cerâmico, equivalente ao lote 01; • Pintura PVA ou acrílica, equivalente ao lote $01 ; \bullet$ Instalação elétrica predial, equivalente ao lote $0 ; \bullet$ Instalação de rede lógica, equivalente ao lote 01; • SPDA equivalente ao lote 02.

Esses quantitativos deveriam constar na CAT, comprovando que a empresa executou esses serviços, além de que deveria apresentar também no seu quadro técnico, profissionais com a comprovação de acompanhamento e ou execução desses serviços ou parecidos. $\mathrm{O}$ edital numa forma de assegurar a proposta de menor preço, no item 8.1.4.1 'dIV.2', para evitar a desclassificação de proposta com oferecimento da planilha mais em conta para o órgão licitante, foi considerado que estará desclassificado apenas a proposta que passar em $15 \%$ do valor unitário da Administração.

Na primeira fase, compareceram um total de 09 empresas, na qual cada representante de suas empresas, puderam analisar os documentos de cada empresa, fazendo suas possíveis alegações, após encerramento da ata, cabe à comissão de licitação investigar as alegações e fazer seu próprio julgamento, na qual das empresas concorrentes, ficou as seguintes considerações. A empresa Torquato Fernandes construções e imobiliária LTDA foi habilitada, a empresa POLC empreendimentos serviços e comercio LTDA habilitada, Versal construção e consultoria LTDA habilitada, Conpac construções e consultoria LTDA habilitada, Construtora MC Correa LTDA habilitada e as empresas Construtora AP Engetech LTDA, Cinzel engenharia Ltda, F.C. engenharia LTDA e MS Pinto engenharia LTDA foram inabilitadas.

Construtora AP Engetech não atendeu aos itens do edital: • 8.1.4.1.II- Capacidade técnicoprofissional- a empresa comprove no seu quadro o profissional registrado que tenha envolvimento nos serviços exigidos no acervo; • 8.1.4.1.III- Capacidade técnico operacional- comprovação de aptidão da empresa com os serviços envolvidos na obra; • 8.1.4.1.IV- Declaração da licitante, indicando o responsável técnico- tendo que apresentar um engenheiro ou arquiteto registrados nos devidos conselhos com a capacidade de execução dos serviços impostos pelo edital.

Cinzel engenharia LTDA não atendeu aos itens: • 8.1.4.1.II; • 8.1.4.1.III; • 8.1.4.1. IV.

F.C engenharia LTDA não atendeu aos itens: • 8.1.4.1.II; • 8.1.4.1.III; • 8.1.4.1.IV; • 8.1.4.2.f- Relação explicita e declaração formal da disponibilidade de equipamentos, veículos e pessoal técnico.

MS Pinto engenharia LTDA não atendeu aos itens: • 8.1.4.1.II; • 8.1.3.6.3- Certidão negativa de falência e recuperação judicial expedida por distribuidor diverso da sede da pessoa jurídica.

Na fase seguinte, da proposta, houveram ainda a desclassificação das empresas POLC e a Construtora MC Correa. A empresa POLC foi desclassificada por apresentar o INSS de $20 \%$ na composição de encargos sociais e ainda apresentou 4,5\% de CPRB na composição de BDI, tendo assim a empresa aplicando uma bitributação do INSS. A empresa MC Correa, a empresa apresentou os 11.7 e 11.18 sem custo para a mão de 
obra, o que claramente foi um erro de planilha, pois na composição da administração a empresa demonstrou esse valor corretamente, contudo foi desclassificada. Ficando apenas o seguinte modelo de empresas.

Tabela 4: Valores para o lote 01.

\begin{tabular}{|l|l|l|}
\hline Ordem & Lote 01 & Valor da proposta \\
\hline 1 a & Conpac & $562.779,59$ \\
\hline $2^{\text {a }}$ & Torquato & $571.112,11$ \\
\hline 3 a & Versal & $600.122,94$ \\
\hline
\end{tabular}

Legenda: Maranhão - concorrência n. 02 (2016).

E no lote 02 ficou apenas a empresa Versal com $\mathrm{R} \$ 141.962,67$ (cento e quarenta e um mil, novecentos e sessenta e dois reais e sessenta e sete centavos), sendo essa a vencedora do lote, e no lote 01 a empresa Conpac por não ter cometido nenhum erro e apresentado menor preço, saiu a vencedora da licitação.

\section{Amostra 07}

Para a sétima amostra, foi coletado os dados da licitação da TJMA (Tribunal de Justiça do Maranhão), tipo de menor preço sob regime da modalidade concorrência $n^{\circ} 03$ de 2016, abertura do certame ocorreu no dia 27 de outubro de 2016, às 10:00 horas. O objeto desta licitação é a Registro de preço para contratação de empresa(s) especializada(s) na prestação de serviços de engenharia civil sob demanda, para atender as necessidades de serviços continuados de manutenção predial, corretiva, incluindo, reparos, adaptações/adequações decorrentes de alterações de layouts, com fornecimento de mão-de-obra e material, nas edificações utilizadas pelo Poder Judiciário do Estado do Maranhão, orçado pelo órgão público no valor de $\mathrm{R} \$ 68.898 .500,57$ (sessenta e oito milhões oitocentos e noventa e oito mil quinhentos reais e cinquenta e sete centavos), licitação é dividida em 08 lotes. Na Tabela 5 temos o resumo desses lotes.

Tabela 5: Resumo dos lotes.

\begin{tabular}{|l|l|}
\hline LO T E S & $\mathrm{V} \mathrm{A} \mathrm{L} \mathrm{O} \mathrm{R}$ \\
\hline LOTE - 01 (Polo Regional São Luís - ADM) & $\mathrm{R} \$ 8.816 .935,15$ \\
\hline LOTE - 02 (Polo Regional São Luís - Juizado) & $\mathrm{R} \$ 8.533 .029,03$ \\
\hline LOTE - 03 (Polo Regional São Luís - FDSC) & $\mathrm{R} \$ 8.461 .240,81$ \\
\hline LOTE - 04 (Polo Regional Imperatriz) & $\mathrm{R} \$ 9.123 .719,15$ \\
\hline LOTE - 05 (Polo Regional Caxias) & $\mathrm{R} \$ 8.852 .761,93$ \\
\hline LOTE - 06 (Polo Regional de Chapadinha) & $\mathrm{R} \$ 8.128 .520,52$ \\
\hline LOTE - 07 (Polo Regional de Pinheiro) & $\mathrm{R} \$ 8.632 .124,84$ \\
\hline LOTE - 08 (Polo Regional de Santa Inês) & $\mathrm{R} \$ 8.350 .169,14$ \\
\hline T O T A L & $\mathrm{R} \$ 68.898 .500,57$ \\
\hline
\end{tabular}

Legenda: Maranhão concorrência n. 03 (2016).

Para a realização desta obra, as empresas interessadas em participar teriam que constar em seus acervos que a licitante executou os serviços de manutenção predial, com características iguais ou semelhantes ao objeto desta licitação, englobando serviços nas áreas de alvenaria, divisórias em gesso comum e drywall, coberturas em telha de fibrocimento e metálicas, revestimentos cerâmicos, forros em PVC, esquadrias e ferragens, soleiras e peitoris, impermeabilização, pintura, instalações elétricas, hidráulicas e sanitárias, cabeamento estruturado, louças e metais dentre outros, totalizando o somatório no mínimo, de $3.000 \mathrm{~m}^{2}$ (três mil quadrados) de área construída, para cada LOTE.

Esses quantitativos deveriam constar na CAT, comprovando que a empresa executou esses serviços, 
além de que deveria apresentar também no seu quadro técnico, profissionais com a comprovação de acompanhamento e ou execução desses serviços ou parecidos. Das empresas participantes ficou o seguinte esquema de inabilitadas das empresas de acordo com o Quadro 3 abaixo:

Quadro 3: Situação de habilitação das empresas.

\begin{tabular}{|c|c|}
\hline Empresas & Situação \\
\hline Modulo engenharia Itda & $\begin{array}{l}\text { Inabilitada } \\
\bullet \quad 7.1 .5 .6\end{array}$ \\
\hline Fênix construções e incorporações Itda & $\begin{array}{lr}\text { Inabilitada } \\
-\quad 7.1 .2 .2 \\
-\quad 7.1 .5 .6\end{array}$ \\
\hline Pinheiro comércio e serviços Itda & $\begin{array}{l}\text { Inabilitada } \\
\text { - } \quad 7.1 .3 .1 " \mathrm{a} \text { " e "b" } \\
\text { - } \quad 7.1 .2 .2 \\
\text { - } \quad 7.1 .5 .1 \\
\text { - } \quad 7.1 .5 .7 \\
\end{array}$ \\
\hline Global serviço e comercio Itda & $\begin{array}{l}\text { Inabilitada } \\
\bullet \quad 7.1 .4 .1 \\
\bullet \quad 7.1 .4 .2 \\
\bullet \quad 7.1 .4 .5 \\
\end{array}$ \\
\hline Colibra construção, locação e serviços Itda & \begin{tabular}{ll}
\multicolumn{2}{l}{ Inabilitada } \\
- & 7.1 .4 .1 \\
- & 7.1 .4 .2 \\
- & 7.1 .4 .3 \\
- & 7.1 .4 .8 \\
- & 7.1 .4 .11 \\
- & 7.1 .5 .1 \\
- & 7.1 .5 .6 \\
- & 7.1 .5 .7
\end{tabular} \\
\hline C \& D Arquitetura, construção e infraestrutura Itda & \begin{tabular}{ll}
\multicolumn{2}{l}{ Inabilitada } \\
- & 7.1 .4 .1 \\
$\bullet$ & 7.1 .4 .2 \\
$\bullet$ & 7.1 .4 .10 \\
- & 7.1 .5 .1 \\
\end{tabular} \\
\hline Agil construções e serviços Itda & \begin{tabular}{ll}
\multicolumn{2}{l}{ Inabilitada } \\
- & 7.1 .4 .1 \\
- & 7.1 .4 .2 \\
- & 7.1 .4 .8 \\
- & 7.1 .2 .2 \\
\end{tabular} \\
\hline Ingara construções Itda & \begin{tabular}{lr}
\multicolumn{2}{l}{ Inabilitada } \\
$-\quad$ & 7.1 .2 .2 \\
- & 7.1 .5 .7
\end{tabular} \\
\hline Claudio ferro arquitetura Itda & \begin{tabular}{lr}
\multicolumn{2}{l}{ Inabilitada } \\
- $\quad 7.1 .5 .6$ \\
$-\quad 7.1 .5 .7$ \\
\end{tabular} \\
\hline
\end{tabular}

Legenda: Maranhão (2016).

De acordo com o edital em vigência, pode-se citar os itens em questão na qual foram listados como os motivos de desclassificação das empresas, logo será exposto aqui apenas os com mais frequências. 7.1.5.6. Certidão Negativa de Condenações por Ato de Improbidade Administrativa; • 7.1.2.2. Prova de Inscrição no Cadastro de Contribuintes Estadual ou Municipal; • 7.1.3.1. Balanço Patrimonial e demonstrações contábeis do último exercício social; • 7.1.5.7. Consulta ao Cadastro de Empresas Inidôneas e Suspensas do Portal de Transparência do Governo Federal; • 7.1.4.1. Apresentação de Atestados de Capacidade Técnico - Profissional; • 7.1.4.2. Apresentação de Atestado (s) de Capacidade Técnica Operacional; • 7.1.4.8. Relação explícita e declaração formal da disponibilidade da licitante de equipamentos, veículos e/ou pessoal técnico especializado, considerados essenciais para o cumprimento do objeto da 
licitação.

Visto a esse modo que muitas empresas cometeram erros por déficit na estrutura da empresa, que é a questão do preparo dos documentos chamados burocráticos e pôr a ausência dos acervos técnicos tanto da empresa quanto do profissional responsável pela possível execução da obra.

\section{Amostra 08}

Para a oitava amostra, foi coletado os dados da licitação da SINFRA (Secretaria de estado de infraestrutura do Maranhão), tipo de menor preço sob regime da modalidade concorrência no 041/2016 CSL/SINFRA, abertura do certame ocorreu no dia 31 de outubro de 2016, no horário das 15:30. O objeto desta licitação é a contratação de empresa especializada para construção do prédio da escola profissional onde funcionará o instituto de educação, ciência e tecnologia do Maranhão - IEMA no município de Chapadinha/MA. Para a realização desta obra, as empresas interessadas em participar teriam que constar em seus acervos: • Execução de Bloco intertravado de concreto; • Fornecimento e montagem de estrutura metálica; • Execução de concreto armado; • Fornecimento e instalação de subestação elétrica de 150kva.

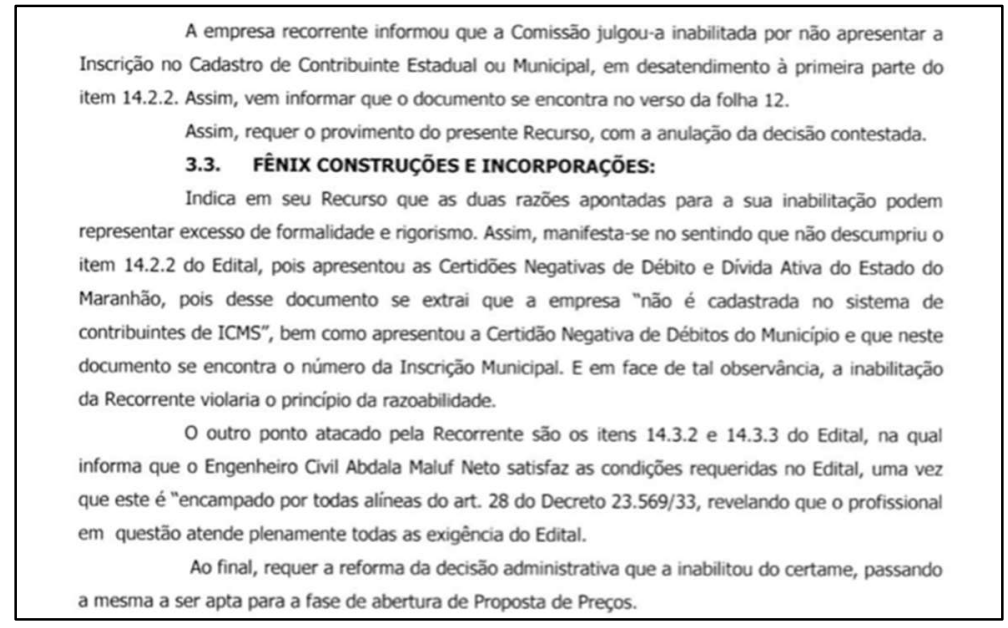

Figura 4: Julgamentos da habilitação.

Esses quantitativos deveriam constar na CAT, comprovando que a empresa executou esses serviços, além de que deveria apresentar também no seu quadro técnico, profissionais com a comprovação de acompanhamento e ou execução desses serviços ou parecidos. No certame foram desclassificadas por falta de acervo técnico as empresas Planejar construções e serviços LTDA-ME, Ergus construções LTDA e Fênix construções e incorporações, na qual entraram com recurso, para tentar ser habilitadas e permanecer na licitação e habilitando as empresas Ires engenharia e a Engetech construtora LTDA.

A empresa Planejar foi inabilitada por apresentar 3 laudos técnicos de execução de subestação, porém as 3 foram menores que a exigida no edital de 150KVA. Tendo ela apresentado subestações com 112,5KVA, CAT n72208/2014, outra com 112,5KVA, CAT n 72209/2014 e a última com 45KVA com a CAT ${ }^{\circ}$ $35131 / / 2011$.

A empresa Ergus foi inabilitada por não obedecer ao item do edital 14.2.2, ou seja, deixou de apresentar a Certidão de inscrições no cadastro de contribuinte estadual ou municipal. A empresa justificou 
alegando que o documento se encontrava impresso no verso da folha 12 , impressão reduzida e ainda se baseou no artigo 43 da lei 8.666/93, apresentando o seguinte:

Art. 43. A licitação será processada e julgada com observância dos seguintes procedimentos:

§ 30 É facultada à Comissão ou autoridade superior, em qualquer fase da licitação, a promoção de diligência destinada a esclarecer ou a complementar a instrução do processo, vedada a inclusão posterior de documento ou informação que deveria constar originariamente da proposta.

E a empresa Fênix foi inabilitada pelo mesmo motivo citado acima da empresa Ergus, além de que o engenheiro eletricista responsável pela CAT da subestação, não havia vínculo com a empresa, na existência de algum contrato, sendo assim a mesma inabilitada, alegou que a Certidão de inscrições no cadastro de contribuinte estadual ou municipal não é solicitada de forma excessiva, ficando ainda declarado que o ISS e ICMS são recolhidos no âmbito da compra das matérias os impostos ficam retidos. A empresa ainda alega que o órgão se apegou ao formalismo e que a ausência não gera prejuízo algum ao ato, e não se manifestou de formalmente sobre a questão da colocação do engenheiro eletricista no quadro da empresa. A comissão licitante acolheu apenas a empresa Ergus construções LTDA, dando-lhe provimento para continuar na licitação.

\section{Amostra 09}

Para a nona amostra, foi coletado os dados da licitação da SINFRA (Secretaria de estado de infraestrutura do Maranhão), tipo de menor preço sob regime da modalidade concorrência nº 019 de 2016, abertura do certame ocorreu no dia 07 de dezembro de 2016, às 09:30 horas.

O objeto desta licitação é a elaboração de projeto executivo de engenharia para obras de melhoramentos, pavimentação e restauração da rodovia estadual ma-020, no trecho compreendido entre entroncamento da br-420 em Rosário e o entroncamento da br-222 no povoado leite, chamada de estrada dos presidentes, com 90,00 km de extensão, orçado pelo órgão público no valor de R\$ 2.125.389,24 (dois milhões, cento e vinte e cinco mil, trezentos e oitenta e nove reais e vinte e quatro centavos) tendo no seu cronograma o prazo de 360 (trezentos e sessenta) dias, para executar a obra.

Para a realização desta obra, as empresas interessadas em participar teriam que constar em seus acervos a execução de Projeto Executivo de Engenharia para Melhoria e Pavimentação, Implantação ou Duplicação Rodoviária com quantidade mínima de $\geq 45 \mathrm{Km}$, apresentando apenas 1 atestado, não podendo valer o somatório. Esses quantitativos deveriam constar na CAT, comprovando que a empresa executou esses serviços, além de que deveria apresentar também no seu quadro técnico, profissionais com a comprovação de acompanhamento e ou execução desses serviços ou parecidos

Após a análise dos documentos das empresas, a comissão deu o parecer habilitando a Entel engenharia e tecnologia LTDA; Geosistemas engenharia e planejamento LTDA, Maia melo engenharia LTDA. Projevias LTDA. - ME, Concorde engenharia LTDA, e inabilitando das empresas Beck de Souza engenharia LTDA, Delbrisa engenharia LTDA, Síntese - sociedade industrial e técnica de serviços de engenharia LTDA e E.M.V. engenharia de construções LTDA. A empresa Delbrisa engenharia foi desclassificada por deixar de 
apresentar o CRC do contador vencido e não apresentar a certidão de inscrição no cadastro contribuinte municipal, e a empresa Beck de Souza foi a ausência da assinatura do "quadro 2", a Beck alegou que haveria outro quadro na qual poderia ter a autenticidade do responsável, e a empresa Delbrisa alegou ter apresentado o CRC atualizado.

Segundo a Comissão, foi possível constar e ter como verdade a alegação da empresa Beck de Souza, dando-a possibilidade de continuar na licitação, enquanto a empresa Delbrisa, foi visto a existência de 2 CRC, um vencido e outro dentro do prazo de validade exigido no edital, contudo não foi possível reaver a questão da certidão de inscrição no cadastro contribuinte municipal, sendo assim continuando inabilitada a empresa Delbrisa. As demais empresas inabilitadas não apresentaram manifestação.

\section{Amostra 10}

Para a décima amostra, foi coletado os dados da licitação da SEMOSP (secretaria municipal de obras e serviços públicos), tipo de menor preço sob regime da modalidade concorrência n 017/2018/CPL/PMSL, abertura do certame ocorreu no dia 31 de julho de 2018, no horário das 14:30. O objeto desta licitação é a Contratação de empresa especializada para conclusão da Praça dos Esportes e da Cultura, localizada na praça do Coroado, orçado pelo órgão público no valor de $\mathrm{R} \$$ 1.649.506,07 (um milhão e seiscentos e quarenta e nove mil e quinhentos e seis reais e sete centavos).

Para a realização desta obra, as empresas interessadas em participar teriam que constar em seus acervos: • Piso em concreto estampado, tendo executado $1.000 \mathrm{~m}^{2}$; • Pavimentação em blocos de concreto serão do tipo 'paver' modelo platô $10 \times 20 \mathrm{~cm}$, tendo executado $600 \mathrm{~m}^{2}$; • Piso laminado em concreto $20 \mathrm{mpa}$, tendo executado $500 \mathrm{~m}^{2} ; \bullet$ Grama batatais em placas, tendo executado $800 \mathrm{~m}^{2}$.

Esses quantitativos deveriam constar na CAT, comprovando que a empresa executou esses serviços, além de que deveria apresentar também no seu quadro técnico, profissionais com a comprovação de acompanhamento e ou execução desses serviços ou parecidos.

Para a avaliação dessa fase de habilitação, houveram a participação de apenas 02 empresas, a empresa SANGAR construções eireli EPP e a empresa EMT empresa manhanense de terraplenagem LTDA EPP, portanto a empresa SANGAR solicitou uma melhor análise do acervo da empresa adversária, onde apresentou 'PISO EM CONCRETO 15 MPA ESP 7CM, c/Junta de Dilatação em Madeira', alegando que não há similaridade com o solicitado no edital, que seria a comprovação de Pavimentação em blocos de concreto serão do tipo 'paver' modelo platô $10 \times 20 \mathrm{~cm}$, tendo executado $600 \mathrm{~m}^{2}$.

A SEMOSP analisou a alegação da SANGAR e emitiu um parecer técnico que a empresa EMT não conseguiu cumprir com os acervos exigidos pelo edital, fazendo com que a empresa SANGAR fosse bemsucedida na sua alegação. Logo após a análise, a comissão da SEMOSP se manifestou com uma decisão ao recurso, dando seu parecer final que a empresa EMT empresa maranhense de terraplenagem LTDA - EPP fosse declarada como inabilitada, não podendo mais participar do certame licitatório. 


\section{DISCUSSÃO}

É possível afirmar pelo estudo de caso, possibilitou um entendimento melhor sobre os processos administrativos, tipos de licitações, modalidade e as fases licitatórias. Notou-se que os itens propostos nos objetivos sobre a questão de as propostas desempenharem uma maior abrangência de desclassificação das empresas foi totalmente desmistificado pela etapa da habilitação.

Com um total de 10 amostras coletadas, foi possível analisar de forma detalhada quais erros cometidos pelos participantes da licitação são mais recorrentes, e além de ter o conhecimento sobre os resultados do julgamento para verificar a posição da comissão, foi devidamente em algumas amostras demonstrado como funciona o processo de recurso, quando a empresa é inabilitada na primeira etapa e visto o posicionamento e até onde é aceitável a questão do recurso. Fato que a medida do recurso se baseia principalmente em normas, leis ou provas que apontem o direito da parte em recurso.

Visto que no resultado detalhando obteve-se o resultado de que as empresas têm uma chance de $61,54 \%$ ser desclassificadas na primeira fase da licitação, que é a fase da habilitação e $38,46 \%$ na fase da proposta, isso quando ocorre a inabilitação dessas empresas. Dos $61,54 \%$ da inabilitação da fase da habilitação estão inclusos os casos dos documentos de habilitação que vimos como exemplo a falta de apresentação de vinculo do empregado responsável pelos acervos técnicos com o empregador, o caso que mais se repete é com o profissional engenheiro elétrico, pois normalmente a empresa é fundada por engenheiro civil e para a empresa pequena, sai caro manter direto o contrato com o profissional, logo é corriqueiro quando a empresa pretende participar de licitação quando existe a necessidade de engenheiro eletricista no quadro da empresa, contratar por período, e a comprovação desse profissional na empresa muitas das vezes é passada de forma negligente.

Ainda sobre a relação dos documentos de habilitação, foi identificado que a Certidão de inscrições no cadastro de contribuinte estadual ou municipal, é um dos casos que se repetiram por mais de uma empresa, assim como a questão de documentos atualizados, dentro da validade, ou ainda a quitação do profissional junto ao Conselho responsável, podendo ser o CREA ou o CAU. Por isso é um fator importante para o bom funcionamento da empresa, ter pessoas responsáveis e compromissadas para manter os documentos atualizados e quitados, para quando for preciso não ocorrer erros por esse caso. Visto que no decreto 9.094/2017, já melhorou de forma razoável as chances de descuidos nos casos da burocracia dos documentos.

No posicionamento dos casos em relação ao acervo técnico, é uma questão em que vai sempre ocorrer de forma a que prejudique às empresas novas no mercado, mas em compensação traz uma quebra de dúvida em relação aos trabalhos a ser executado, pois a empresa com o acervo demonstra conhecimento e experiência sobre o serviço cobiçado. O que é mais comum é ver que em licitações na qual já exigem um acervo mais restrito, mais elaborado, o número de inabilitação é altíssimo ou o número de participantes é bem pouco, isso acontece devido ao que já foi mencionado, a questão de empresas novas sem os acervos necessários para adentrar ao mercado das licitações. 


\section{CONCLUSÕES}

Pode-se dizer que os erros cometidos na fase de propostas são erros humanos, pois foram cometidos por falta de informação ou atenção de quem a elabora, mas quando se fala na fase de habilitação os erros acontecem por a empresa não realmente ter a documentação necessária ou o acervo exigido, mas mesmo assim tentam a sorte.

Logo em base do que foi apresentado no estudo, é possível conhecer os principais motivos que afetam as empresas, e com isso toma-se um cuidado extra para que não torne a acontecer, apresentado ainda modelo argumentativo embasado em leis para recursos nos casos de inabilitação, que mesmo em primeiro parecer ter sido inabilitada, foi possível reverter o caso.

\section{REFERÊNCIAS}

ALEXANDRE, R.; DEUS, J.. Direito administrativo. 3 ed. São Paulo: Método São Paulo, 2017.

BRASIL. Lei n.8.666 de 21 de junho de 1993, artigo 22. Modalidades de Licitações. Brasília: DOU, 1993.

BRASIL. Lei n.8.666 de 21 de junho de 1993, artigo 27 Seção II. Habilitação. Brasília: DOU, 1993.

BRASIL. Lei n.8.666 de 21 de junho de 1993, artigo 37, inciso XXI. Institui normas para licitações e contratos da Administração Pública e dá outras providências. Brasília: DOU, 1993.

BRASIL. Lei n.10.520 de $\mathbf{1 7}$ de julho de 2002. Institui, no âmbito da União, Estados, Distrito Federal e Municípios, nos termos do art. 37, inciso XXI, da Constituição Federal, modalidade de licitação denominada pregão, para aquisição de bens e serviços comuns, e dá outras providências. Brasília: DOU, 2002.

BRASIL. Lei n.12.462 de 4 de agosto de 2011. Institui o Regime Diferenciado de Contratações Públicas - RDC; altera a Lei no 10.683, de 28 de maio de 2003, que dispõe sobre a organização da Presidência da República e dos Ministérios, a legislação da Agência Nacional de Aviação Civil (Anac) e a legislação da Empresa Brasileira de Infraestrutura Aeroportuária (Infraero). Brasília: DOU,2011.

CARVALHO FILHO, J. S.. Manual de Direito Administrativo.
29 ed. São Paulo: Atlas, 2015

MARANHÃO. Comissão Central Permanente de Licitação. Propostas das Empresas. Concorrência n.006. São Luís: CCL, 2016.

MARANHÃO. Comissão Central Permanente de Licitação. Valores parciais das obras. Concorrência n.31. São Luís: CCL, 2016.

MARANHÃO. Agência Estadual de Pesquisa Agropecuária e Extensão Rural do Maranhão. Processo Administrativo n. 094056: Aviso de Julgamento da habilitação. São Luís, 2018.

MARANHÃO. Tribunal de Justiça do Maranhão. Aviso de julgamento de habilitação das empresas. São Luís: TJMA, 2018.

MARANHÃO. Tribunal de Justiça do Maranhão. Valor dos Lotes. Concorrência n.02. São Luís: TJMA, 2016.

MARANHÃO. Tribunal de Justiça do Maranhão. Resumo dos Lotes. Concorrência n.03. São Luís: TJMA, 2016.

TOLOSA FILHO, B.. Licitações: Comentários, teorias e prática. Rio de Janeiro: Forense, 1997.

TORRES, R. C. L.. Leis de Licitações Públicas comentadas.7 ed. Salvador: JusPodivm, 2015.

A CBPC - Companhia Brasileira de Produção Científica (CNPJ: 11.221.422/0001-03) detém os direitos materiais desta publicação. Os direitos referem-se à publicação do trabalho em qualquer parte do mundo, incluindo os direitos às renovações, expansões e disseminações da contribuição, bem como outros direitos subsidiários. Todos os trabalhos publicados eletronicamente poderão posteriormente ser publicados em coletâneas impressas sob coordenação da Sustenere Publishing, da Companhia Brasileira de Produção Científica e seus parceiros autorizados. Os (as) autores (as) preservam os direitos autorais, mas não têm permissão para a publicação da contribuição em outro meio, impresso ou digital, em português ou em tradução. 